\title{
Shape of the Heat Exchanger Pipe in the Heating and Cooling Systems Based on Heating Pipe Technology in Aircraft
}

\author{
Vladimir Knyazev ${ }^{1, *}$, and Evgeny Nikulchev ${ }^{2,3}$ \\ ${ }^{1}$ Moscow Institute of Physics and Technology, Higher School of Systems Engineering, 141701 Dolgoprudny, Russia \\ ${ }^{2}$ Moscow Technological Institute, 119334 Moscow, Russia \\ ${ }^{3}$ Moscow Technological Institute MIREA, 119454 Moscow, Russia
}

\begin{abstract}
The main purpose of this article is experimental research aimed to find the required shape of the heat exchanger pipe manufactured by deformation cutting technology for increased efficiency during operation in the heating and cooling systems based on heating pipe technology in aircraft. In the result, recommendations were made to use the different shapes of the heat exchanger pipe in the heating and cooling systems based on heating pipe technology in aircraft.
\end{abstract}

\section{Introduction}

There are many ways to use heating pipe technology in the aircraft's equipment. The main principle of heating pipe technology is described in the book [1]. The article [2] describes the in-flight entertainment cooling system, which is used on commercial boards and provides audio, video, internet, multimedia, phone services. This system is based on the heating pipes and could be installed under each passenger's seat in a modern aircraft. The patent [3] describes the passive cooling system for the aircraft's transmission using the mast mounted heating pipes. The patent [4] shows a cooling system based on heating pipes for helicopter gearbox. The heating pipe is also used in heating systems, such as passive anti-icing systems in aircrafts.

One of the methods to increase heat transfer in the heat exchanger pipe and simultaneously save the required dimensions of the pipe is deformation cutting technology. The article [5] describes requirements and technology for fin application to the long pipe on the basis of hybrid deformation and cutting. In another article, [6] the results are described from an experimental research of heat transfer in the microstructured surfaces obtained by using the deforming cutting method.

The aim of the experiment is to evaluate the effectiveness of deformation cutting technology used in manufacturing of the heat exchanger pipes in the heating and cooling systems based on a heating pipe technology in aircraft.

\section{Types of the heat exchanger pipes}

Technology of the deformational cutting was chosen as a perspective method to improve effectiveness in the heat exchanger pipes. All samples have following parameters: $20 \mathrm{~mm}$ diameter, $2.5 \mathrm{~mm}$ wall thickness, made of steel
B20. The length of all the samples is $1100 \mathrm{~mm}$. The inner pipe surface area is $0.0471 \mathrm{~m} 2$. Four samples were provided for the experiment; with different outer surfaces are obtained using deformation cutting technology (Fig. 1). The main characteristics of the pipes are showen in the Table 1.

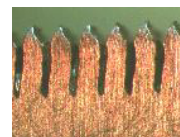

№1

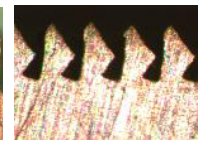

№2

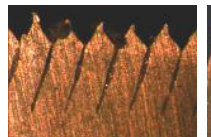

№3

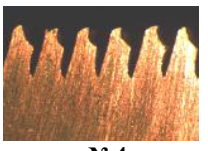

№4
Fig. 1. Types of microstructured pipes ( Type №1, №2, №3, №4).

Table 1. Characteristics of the microstructured pipes

\begin{tabular}{|c|l|l|l|l|}
\hline Parameters /Types & №1 & №2 & №3 & №4 \\
\hline Step of the edges, mm & 0,4 & 0,5 & 0,4 & 0,4 \\
\hline $\begin{array}{c}\text { The average height of the } \\
\text { structure, mm }\end{array}$ & 0,95 & 0,75 & 0,65 & 1,15 \\
\hline $\begin{array}{c}\text { The average width of the } \\
\text { intercostal gap, } \mu \mathrm{m}\end{array}$ & 130 & $\begin{array}{l}250 / 1 \\
00\end{array}$ & 100 & 40 \\
\hline $\begin{array}{c}\text { Deviation from the vertical } \\
\text { ribs }\end{array}$ & 0 & 0 & 15 & 15 \\
\hline
\end{tabular}

\section{Experimental setup and measurement procedure}

The experimental setup is imitating the operation of the two phase heating pipe circuit. It consists of two independent circuits. Thermal energy comes from the trunk-heating pipe to the first circuit (the heat exchanger pipe). Through the heat exchanger pipe, energy is

Corresponding author: vladimir.knzv@gmail.com

(C) The Authors, published by EDP Sciences. This is an open access article distributed under the terms of the Creative Commons Attribution License 4.0 (http://creativecommons.org/licenses/by/4.0/). 
transmitted to the small amount of low-boiling liquid, located in the second circuit. Pressure inside the thermal panel is reduced to $30-50 \mathrm{kPa}$. Therefore low-boiling liquid begins to boil at 30-35 degrees Celsius. The resulting steam begins to rise up inside the thermal panel and condenses in the inner surface of the second circuit. During condensation, thermal energy is transmitted to the surface of the second circuit and condensate flows downward due to gravity, after that the cycle repeats. According to that, thermal energy is transmitted from the trunk heating pipe to the surface of the second circuit, which respectively transmits this energy.

The experiments were carried out at the setup (Fig. 2) consisting of the following components. In the first circuit, hot water flows from the local heating system into the testing pipe (3). The thermal sensors (9) measure the input and output temperatures in the testing pipe. The flow meter (10) measures the water flow in the testing pipe. In the second circuit there are: condenser (1), where vaporized low-boiling liquid condenses, transparent pipe (2) made of plastic, pipelines (4), valves (5) for flow control, condensate container (6), vacuum gaskets (7), supply vessel (8) to support the required level of liquid in the transparent pipe during the experiment, pressure sensor (11) and vacuum pump (12) for setting required pressure in the second circuit.

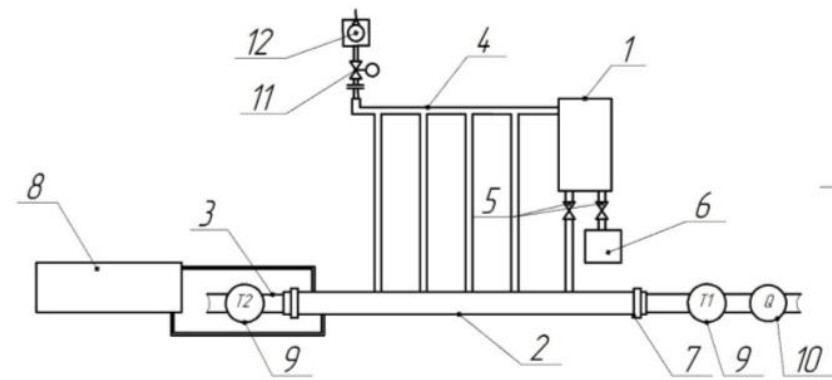

Fig. 2. Experimental setup scheme.

In the testing pipe, the stationary flow rate and temperature of water are set. The second circuit is evacuated from vapor pressure of low-boiling liquid, which is filled into the transparent pipe. In this case, it was isopropyl alcohol. The condensate container's valve is closed; the system has reached the stationary operating condition.

Next the condensate container's valve is opened and the transparent pipe's valve is closed at the same time. Condensate begins to drain into the condensate container. Measured values during the experiment are: the mass of evaporated isopropyl alcohol depending on the time, input and output temperatures of the water in the testing pipe, the water flow rate, pressure and level of isopropyl alcohol in the transparent pipe.

The graphs of the mass of evaporated isopropyl alcohol depending on time are obtained based on the results of the experiment. The graph is divided into the sections, corresponding to the different levels of isopropyl alcohol in the transparent pipe. After that, the angular inclination $\mathrm{dm} / \mathrm{dt}$ is derived at each site. Thermal power of the pipe is calculated according to the formula:

$$
W=q \frac{d m}{d t}
$$

The pipes with different outer surfaces are compared to the standard pipe with the smooth surface. The relation between the thermal power and temperature in the testing pipe are obtained for different immersion levels of isopropyl alcohol in the testing pipe. The most revealing immersion level (Figure 3) was found after several iterations and it was studied more thoroughly.

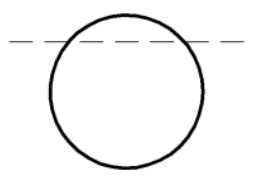

Immersion 1

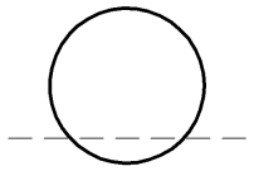

Immersion 2
Fig. 3. Immersion levels.

\section{Results}

For the immersion level 1, all of the test samples worked loudly in the nucleate boiling regime. The pipes manufactured by deformation cutting technology showed the increased heat output, more than $15-20 \%$ higher than the standard pipe. The experimental data is shown in the Fig. 4.

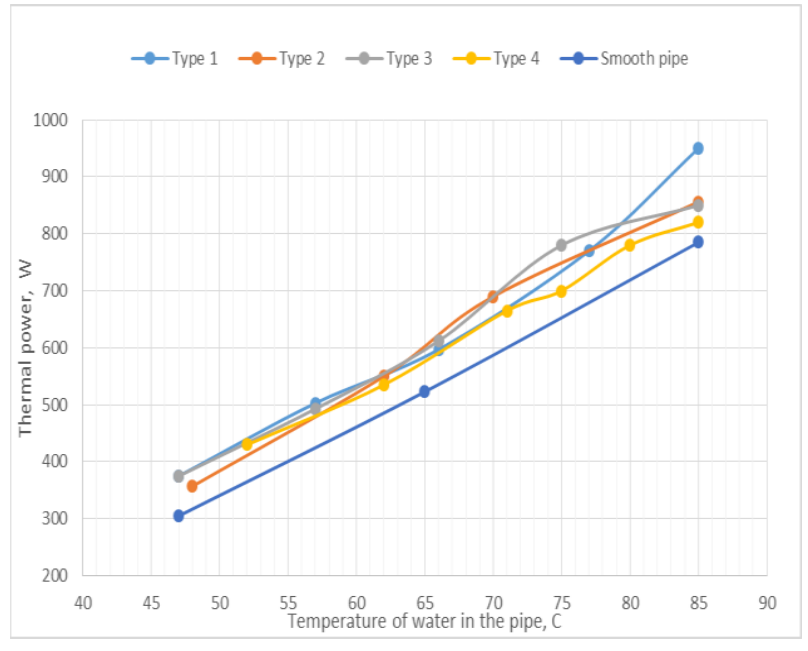

Fig. 4. Immersion level 1.

For the immersion level 2, all the pipes manufactured by deformation cutting technology showed significantly greater heat output (from $30 \%$ to $100 \%$, depending on the temperature) than the standard pipe with the smooth surface. This is because the pipes manufactured by deformation cutting technology have high thermal conductive capillary channels. Evaporation takes place within the entire surface of the pipes. At the same time, different types of surfaces display different features.

For the type 1, at the temperatures up to 65 degrees Celsius, the pipe actively evaporates alcohol from the entire surface. Film boiling occurs, which significantly reduces the noise during operation. In the range of 65-75 
degrees Celsius the capillary channels begin to dry out, parts of the pipe are no longer wet. In result, heating power does not increase with increasing temperatures. Film boiling continues at the temperatures of over 75 degrees Celsius, the process follows to the active phase of the nucleate boiling. In this case, since the gap between the pipe and the inner surface of the transparent pipe is sufficiently small, and the formed spray covered the entire surface of the pipe, the capacity significantly increases. For the types 2 and 3, at the temperatures up to 65 degrees Celsius, the pipes have similar specifications as the type 1 . At the temperature of over 65 degrees Celsius, the nucleate boiling begins, so the power failure is not observed. For the type 4 , the surface evaporation continues to up to 80 degrees Celsius, and the capillary channels do not dry out. At the high temperatures (more than 80 degrees Celsius), the process follows to the nucleate boiling phase. The experimental data is shown in the Fig. 5.

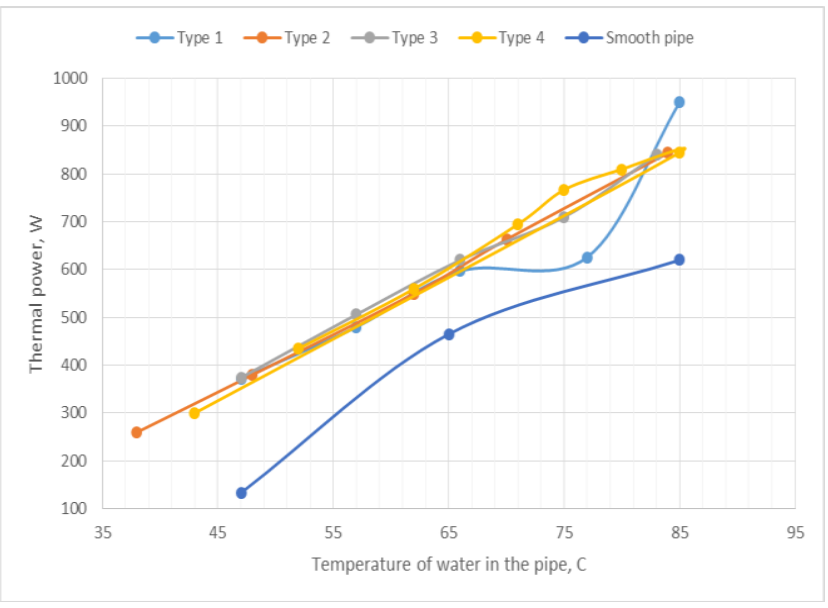

Fig. 5. Immersion level 2.

\section{Conclusions}

This article described the experiment studying features of the pipes manufactured by deformation cutting technology for the heat exchanger pipes used in the heating and cooling systems, based on heating pipe technology in aircraft. For the immersion level 1, the pipes manufactured by deformation cutting technology showed the increased heat output, more than $15-20 \%$ higher than the standard pipe. For the immersion level 2, the sample 1 has the power failure observed in the heating water temperature range of about 65-75 degrees Celsius. The samples 2 and 3 can significantly improve the performance of the heat exchangers and reduce the noise over a wide range of temperatures. Sample 3 showed the best heat transfer features, among all samples.

The heat exchange surface, similar to the surface 3, can be recommended for using as a part of a system based on a heating pipe technology. The heat exchange surface obtained by deformation cutting technology may be used in the heating and cooling systems, based on a heating pipe technology in aircraft to increase the heat transfer and reduce the noise during operation.

\section{References}

1. D. Peter, D. Reay, Heat pipes (Elsevier, 2012)

2. Sarno C. et al., Applied Thermal Engineering, 51(1), 764-769 (2013)

3. R.T. Ehinger, M.A. McGlaun, Passive cooling of transmission using mast mounted heat pipes, Patent. 8985517. (2015)

4. M.A. McGlaun, K.M. Jackson, Helicopter gearbox auxiliary cooling system, Patent 9272777 USA. (2016)

5. N.N. Zubkov, Russian Engineering Research, 35(11), 859-863 (2015)

6. I.A. Popov, Thermal Engineering, 60(3), 157-165 (2013) 